\title{
Sphingosine kinase-1 predicts overall survival outcomes in non-small cell lung cancer patients treated with carboplatin and navelbine
}

\author{
MARIAM GACHECHILADZE ${ }^{1}$, TOMÁŠ TICHÝ ${ }^{1}$, VÍTĚZSLAV KOLEK ${ }^{2}$, IVONA GRYGÁRKOVÁ², \\ JIŘÍ KLEIN ${ }^{3}$, GIORGI MGEBRISHVILI ${ }^{1}$, GVANTSA KHARAISHVILI ${ }^{1}$, MÁRIA JANÍKOVÁ ${ }^{1}$, PETRA SMIČKOVÁ ${ }^{2}$, \\ LUCIA CIERNA $^{4}$, STUART PITSON ${ }^{5}$, MARIE-LISE MADDELEIN ${ }^{6}$, OLIVIER CUVILLIER ${ }^{6,7^{*}}$ and JOZEF ŠKARDA $^{1 *}$ \\ ${ }^{1}$ Department of Clinical and Molecular Pathology, Institute of Molecular and Translational Medicine, Faculty of Medicine and \\ Dentistry, Palacký University, 77515 Olomouc; ${ }^{2}$ Department of Tuberculosis and Respiratory Diseases; ${ }^{3} 1$ st Department of \\ Surgery, Faculty of Medicine and Dentistry, Palacký University and Faculty Hospital in Olomouc, 77900 Olomouc; \\ ${ }^{4}$ Faculty of Medicine and Dentistry, Palacký University Olomouc, 77515 Olomouc, Czech Republic; ${ }^{5}$ Centre for \\ Cancer Biology, University of South Australia and SA Pathology, Adelaide SA5000, Australia; \\ ${ }^{6}$ Institut de Pharmacologie et de Biologie Structurale, Université de Toulouse, CNRS, UPS, \\ 31077 Toulouse; ${ }^{7}$ Equipe Labellisée Ligue contre le Cancer, 75013 Paris, France
}

Received May 14, 2018; Accepted April 5, 2019

DOI: $10.3892 / \mathrm{ol} .2019 .10447$

\begin{abstract}
Sphingosine 1-phosphate (S1P) is a bioactive lipid metabolite associated with cancer cell proliferation, survival, migration and regulation of tumor angiogenesis in various cellular and animal models. Sphingosine kinase-1 (SphK1) and S1P lyase are the main enzymes that respectively control the synthesis and degradation of S1P. The present study analyzed the prognostic and predictive value of SphK1 and S1P lyase expression in patients with non-small cell lung cancer (NSCLC), treated with either surgery alone or in combination with adjuvant carboplatin and navelbine. Formalin-fixed, paraffin-embedded tissue samples from 176 patients with NSCLC were stained immunohistochemically using antibodies against SphK1 and S1P lyase, and their expression was correlated with all available clinicopathological factors. Increased expression of SphK1 was significantly
\end{abstract}

Correspondence to: Dr Jozef Škarda, Department Clinical and Molecular Pathology, Institute of Molecular and Translational Medicine, Faculty of Medicine and Dentistry, Palacký University, Hněvotínská 3, 77515 Olomouc, Czech Republic

E-mail: jojos@email.cz

Dr Olivier Cuvillier, Institut de Pharmacologie et de Biologie Structurale, Université de Toulouse, CNRS, UPS, Unité Mixte de Recherche 5089, 205 Route de Narbonne, 31077 Toulouse, France E-mail: olivier.cuvillier@inserm.fr

*Contributed equally

Key words: chemotherapy, sphingosine 1-phosphate, survival, relapse, prognosis associated with shorter overall and disease free survival in patients treated with adjuvant platinum-based chemotherapy. No prognostic relevance for S1P lyase expression was observed. Collectively, the results suggest that the immunohistochemical detection of SphK1 may be a promising predictive marker in NSCLC patients treated with adjuvant platinum-based chemotherapy.

\section{Introduction}

Non-small cell lung cancer (NSCLC) accounts for $~ 85 \%$ of all lung cancer cases which is the leading cause of cancer related mortality in the world and the second most common cause of death in developed countries, after cardiovascular diseases (1). Several meta-analyses of data from large randomized controlled trials support the view that cisplatin-based adjuvant chemotherapy alone or in combination with neoadjuvant treatment regimens provides a significant survival advantage for stage IB-III NSCLC patients (2-5). However, individual patient outcomes for any given regimen is still highly uncertain and overall survival remains only $15 \%$ across all stages. One of the main reasons for unsatisfactory survival rates in patients with lung cancer is intrinsic or acquired multidrug resistance (MDR). Multiple cellular mechanisms are involved in MDR in vivo and these are partially reflected by in vitro chemoresistance profiles of NSCLC cells (6-11). Research on MDR mechanisms has been mainly on proteins involved in membrane transport, cell cycle and DNA repair pathways but recently, lipid metabolites including sphingolipids, have emerged as an important player in a number of fundamental biological processes with relevance to cancer pathogenesis and therapy (12).

Sphingolipids are a family of membrane lipids with structural roles in the regulation of the fluidity and sub-domain 
structure of the lipid bilayers (13). They are metabolized, giving, rise to signaling molecules such as ceramide, sphingosine and sphingosine 1-phosphate (S1P) that are associated with cellular activities crucial for health and disease, notably in cancer (14). The generation of endogenous ceramide and/or sphingosine in response to stress stimuli is associated with senescence, growth arrest and apoptosis $(15,16)$. In contrast, S1P plays a key role in mediating cell proliferation, survival, migration and angiogenesis (17-19). It is one of most important sphingolipid metabolites as it is involved in the onset or progression of pathological conditions such as autoimmune diseases, cardiovascular conditions, diabetes and cancer (20).

By converting sphingosine into S1P, the sphingosine kinase-1 isoform (SphK1) (21) alters the ceramide/sphingosine/S1P balance (22). It effectively regulates drug-induced apoptosis and serves as a chemotherapy/radiotherapy sensor in both cell cultures and animal models of various tumors (23-28) including NSCLC $(29,30)$.

Several studies have examined the prognostic and predictive value of SphK1 in solid tumors. In a series of 48 malignant astrocytomas, SphK1 mRNA expression levels correlated with patient survival, with a three-fold increase in median survival in patients with low compared to high expression (31). A recent meta-analysis including thirty-four studies of SphK1 expression in 4,673 patients showed that there was a significant difference in SphK1 expression between cancer, normal tissue adjacent to cancer and benign tissues, as well as different cancer types (32). In addition, SphK1 expression was associated with 5-year and overall survival rates in breast, gastric and other cancers (32). The prognostic value of SphK1 was confirmed in breast cancer where the upper quartile of mRNA SphK1 expression correlated with poor prognosis, irrespective of the estrogen receptor status (33). Assessing S1P content has also been postulated to have diagnostic potential in ovarian cancer, as shown by a significant increase in the product of its activity, in ascites $(34,35)$. A significant increase in both SphK1 expression and enzymatic activity has also been found to be correlated with aggressiveness in prostate cancer specimens at the time of surgery $(34,35)$.

In lung cancer tissue, increased expression of mRNA and protein levels of SphK1 is also seen, compared to adjacent normal lung tissue, and increased SphK1 expression was significantly correlated with tumor progression and poor survival in patients with NSCLC (30). In NSCLC cell cultures, enforced expression of SphK1 significantly inhibited doxorubicin- and docetaxel-induced apoptosis, and is associated with upregulation of the antiapoptotic proteins Bcl-xl, c-IAP1, c-IAP2, and TRAF1 (30). In contrast, silencing SphK1 expression or inhibiting SphK1 activity with a pharmacological inhibitor significantly enhanced the sensitivity of NSCLC cells to apoptosis induced by chemotherapeutics both in vitro and in vivo (30). Moreover, overexpression of SphK1 is associated with activation of the PI3K/Akt/NF- $x$ B pathway, inhibition of which abrogates the antiapoptotic effect of SphK1 in NSCLC cells (30).

S1P can be irreversibly degraded by the S1P lyase (S1P lyase) which is highly conserved throughout evolution and is required for the maintenance of physiological levels of S1P and other sphingolipid intermediates (36). S1P lyase expression potentiates apoptosis in response to DNA damage and other stressful stimuli through a cascading mechanism that involves p53, PIDD and caspase-2 (37). Enforced expression of S1P lyase in HEK293 and A549 human lung cancer cells increased sensitivity to cisplatin and carboplatin (38). The first piece of evidence of the loss of S1P lyase expression in a human neoplasm was reported in prostate cancer patients where an inverse correlation was found between both SphK1 and S1P lyase expression and activity, suggesting an overall tumor increase in S1P (27).

As the prognostic role of SphK1 in NSCLC needs further validation and given the dearth of literature on SphK1 expression in patients with adjuvant platinum-based chemotherapy, our primary aim was evaluate the prognostic and predictive value of SphK1 expression. We also analyzed S1P lyase expression for the first time in NSCLC patients.

\section{Patients and methods}

Patients and samples. A total of 176 archival formalin-fixed, paraffin-embedded (FFPE) tissue samples from an NSCLC patient cohort were acquired from the University Hospital in Olomouc. Informed, written consent for the use of tissues and clinical data was obtained from all participants and the studies were carried out according to the latest Declaration of Helsinki. In addition, the present study was approved by the Ethics Committee of University Hospital Olomouc and Medical Faculty, Palacký University (Olomouc, Czech Republic) on June 2011. Patients were diagnosed and underwent subsequent radical surgery between 1996 and 2000 and 2005-2011. Slides, with routinely stained sections from each case, were re-examined by two independent pathologists and re-classified according to the WHO classification of tumors (2015). The cohort consisted of 122 men and 54 women, of whom, 51 patients were in clinical stage I, 23 in stage II, and 84 in stage III and 8 in stage IV. A total of 95 patients had received adjuvant chemotherapy (aCHT), of whom 21 were treated with the combination of cisplatin and navelbine (18 patients with $4 x$ cycles, 2 patients with $3 x$ cycles an 1 patient with $1 \mathrm{x}$ cycle), 71 patients were treated with the combination of carboplatin and navelbine (64 patients with $4 x$ cycles, 5 patients with $3 x$ cycles and 2 patients with $1 \mathrm{x}$ cycle). Of the remaining three patients, one was treated with the combination of carboplatin and gemcitabine (4x cycles), one with carboplatin and doxorubicin (4x cycles) and one with carboplatin and paclitaxel (4x cycles). Detailed characteristics of patients are given in Tables I and II. Disease-free survival (DFS) was determined as the interval from diagnosis to disease recurrence, with a median of 27 months (25\% and $75 \%$ quartiles; 8 and 130 months, respectively). Overall survival (OS) was determined as the time from diagnosis to disease specific death (median, 38 months; $25 \%$ and $75 \%$ quantiles; 9 and 140 months, respectively).

Immunohistochemistry. Formalin-fixed and paraffin-embedded (FFPE) specimens were cut in $4 \mu \mathrm{m}$ sections, mounted on silane-coated slides, deparaffinized in xylene and rehydrated by washing in serial dilutions of ethanol. Antigen retrieval was performed in an automatic multifunctional microwave tissue processor (T/T MEGA) at $95^{\circ} \mathrm{C}$ for $5 \mathrm{~min}$, using citrate buffer at $\mathrm{pH}$ 6.0. Endogenous 
Table I. Clinicopathological characteristics of NSCLC patients treated with surgery only.

\begin{tabular}{|c|c|c|}
\hline $\begin{array}{l}\text { Clinicopathological } \\
\text { characteristics }\end{array}$ & Total $n(n=78)$ & Percent $(\%)$ \\
\hline \multicolumn{3}{|l|}{ Age, years } \\
\hline$\leq 64$ & 44 & 56.4 \\
\hline$>64$ & 34 & 43.6 \\
\hline \multicolumn{3}{|l|}{ Gender } \\
\hline Female & 19 & 24.4 \\
\hline Male & 59 & 75.6 \\
\hline \multicolumn{3}{|l|}{ Histology } \\
\hline $\mathrm{ADC}$ & 39 & 50.0 \\
\hline SCC & 28 & 35.9 \\
\hline $\mathrm{LCC}$ & 11 & 14.1 \\
\hline \multicolumn{3}{|l|}{ Grade } \\
\hline G1 & 14 & 17.9 \\
\hline G2 & 27 & 34.6 \\
\hline G3 & 34 & 43.6 \\
\hline ANP & 3 & 3.8 \\
\hline \multicolumn{3}{|l|}{ TNM stage } \\
\hline I & 23 & 29.5 \\
\hline II & 6 & 7.7 \\
\hline III & 34 & 43.6 \\
\hline IV & 5 & 6.4 \\
\hline Missing & 10 & 12.8 \\
\hline \multicolumn{3}{|l|}{$\mathrm{T}$} \\
\hline 1 & 28 & 35.9 \\
\hline 2 & 25 & 32.1 \\
\hline 3 & 9 & 11.5 \\
\hline 4 & 6 & 7.7 \\
\hline Missing & 10 & 12.8 \\
\hline \multicolumn{3}{|l|}{$\mathrm{N}$} \\
\hline 0 & 43 & 55.1 \\
\hline 1 & 10 & 12.8 \\
\hline 2 & 14 & 17.9 \\
\hline 3 & 1 & 1.3 \\
\hline Missing & 10 & 12.8 \\
\hline \multicolumn{3}{|l|}{ M } \\
\hline 0 & 63 & 80.8 \\
\hline 1 & 4 & 5.1 \\
\hline 2 & 1 & 1.3 \\
\hline Missing & 10 & 12.8 \\
\hline
\end{tabular}

NSCLC, non-small cell lung cancer; ADC, adenocarcinoma; SCC, squamous cell carcinoma; LCC, Large cell carcinoma; TNM, tumor, node, metastases.

peroxidase activity was blocked with $0.3 \%$ hydrogen peroxide for $15 \mathrm{~min}$. Nonspecific binding was blocked with 5\% horse serum in phosphate buffered saline (PBS). Sections were incubated in primary antibody against SphK1 (38) and S1P lyase (cat. no. HPA023086; Sigma-Aldrich). Specific binding was visualized using the Envision dual link system (Dako).
Table II. Clinicopathological characteristics of NSCLC patients treated with adjuvant chemotherapy.

Clinicopathological

characteristics Total $\mathrm{n}(\mathrm{n}=95) \quad$ Percent $(\%)$

\section{Age, years}

$\leq 64$

50.5

$>64$

47

49.5

Gender

Female

35

36.8

Male

60

63.2

Histology

ADC

SCC

79.5

$\mathrm{LCC}$

23.1

Grade

G1 9

9.5

G2

21.1

G3

65.3

ANP

4.2

TNM stage

I

29.5

II

17.9

III

49.5

IV

T

1

11.6

2

11

11.6

63

66.3

3

13.7

4

N

0

46.3

44

21.1

1
2

2
3

3
$M$

M

31.6

30

1

1.1

93

97.9

1

2.1

NSCLC, non-small cell lung cancer; ADC, adenocarcinoma; SCC, squamous cell carcinoma; LCC, Large cell carcinoma; TNM, tumor, node, metastases.

IHC stained slides were evaluated by three independent pathologists (J.S., T.T., M.G.) and scored according to the histoscore method ( $\mathrm{H}$ score method). The histoscore grades staining intensity as negative (0), weak (1), moderate (2) and strong (3) and then multiplies the percentage of tumor cells within each category. The histoscore range is from 0 (minimum) to 300 (maximum). Agreement between observers was calculated using an interclass correlation coefficient.

Statistical analysis. Correlations between the levels of examined proteins and survival parameters of the patients 


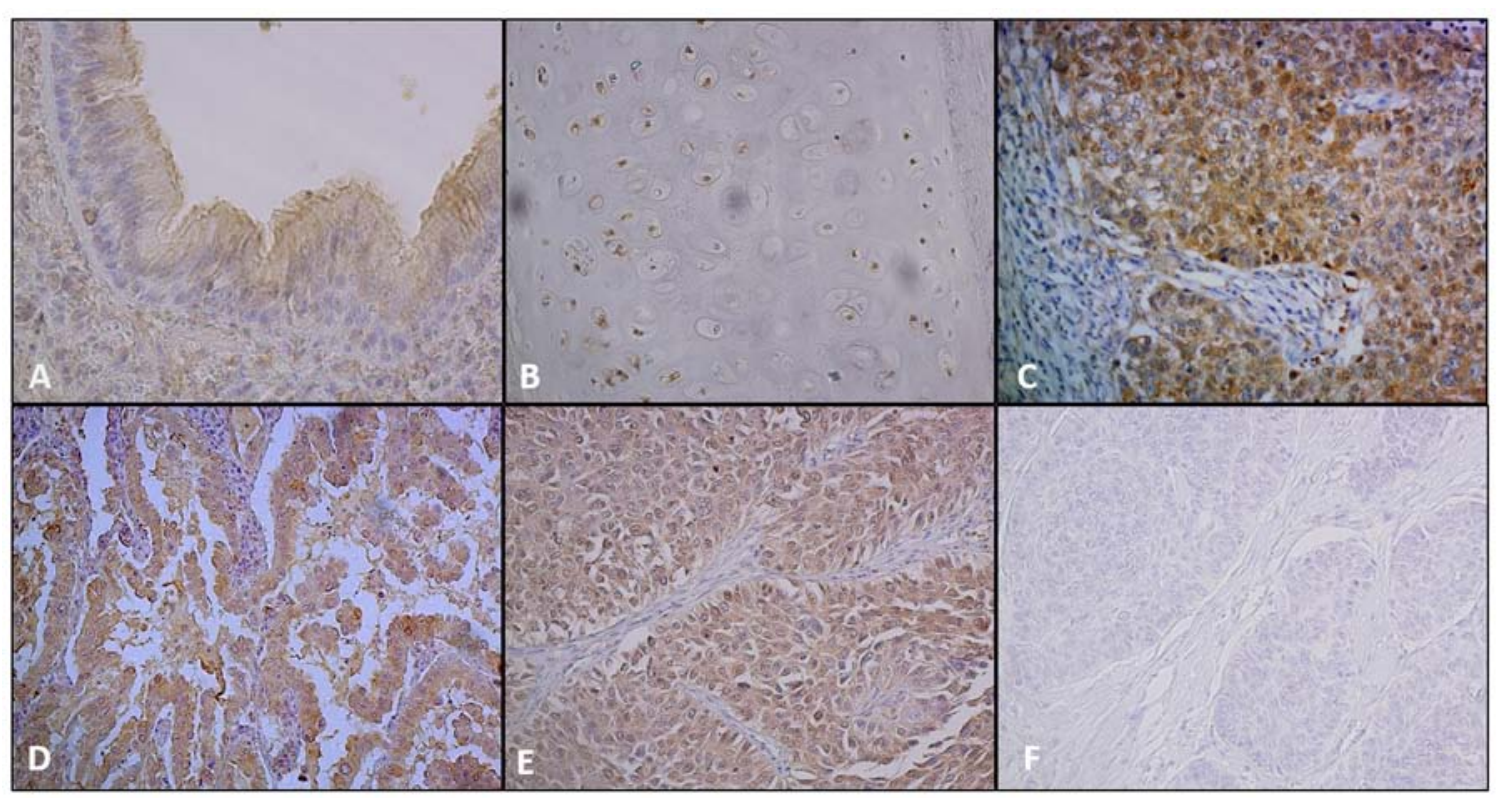

Figure 1. SphK1 staining in normal adjacent and NSCLC tissues. (A) SphK1 staining in normal pseudo-stratified columnar epithelial cells of the bronchiole. (B) Bronchiolar cartilage (IHC staining; magnification, x200). (C) SphK1 staining in adenocarcinoma of the lung, (D) squamous cell carcinoma of the lung and (E) large cell carcinoma of the lung. (F) Matched Immunoglobulin G control (IHC staining; magnification, x200). NSCLC, non-small cell lung cancer; IHC staining, immunohistochemical staining; SphK1, sphingosine kinase-1.

and their clinicopathological features were analyzed using statistical software IBM SPSS statistics v.22 (IBM Corp., Armonk, NY, USA). The Kruskal-Wallis test with Bonferroni's correction was applied for nonparametric comparisons of independent groups. For survival analysis, Kaplan-Meier curves were calculated, and tests of statistical significance were based on log-rank statistics. $\mathrm{P}<0.05$ was considered to indicate a statistically significant difference.

\section{Results}

Immunohistochemical distribution of SphK1 and S1P lyase in normal adjacent and NSCLC tissue. Immunohistochemical staining of normal adjacent lung tissue and the distribution of SphK1 and S1P lyase were examined in several formalin-fixed paraffin-embedded tissue sections from non tumoral regions of the lung. Normal pseudo-stratified columnar epithelial cells in bronchiole (Fig. 1A) stained very intensely on the apical surface at the point of ciliary attachment for SphK1. The staining of SphK1 in bronchiolar cartilage, is shown in Fig. 1B. Interestingly, SphK1 levels appear to be related to chondrocyte maturation. Although immature chondrocytes showed moderate staining for SphK1, mature chondrocytes were devoid of staining. Alveolar parenchyma and type II pneumocytes exhibited a weak staining for SphK1 (not shown). Moderate to strong staining of S1P lyase was shown in normal pseudo-stratified columnar epithelial cells and type II pneumocytes (Fig. 2A and B).

NSCLC samples exhibited various immunostaining patterns for SphK1 (Fig. 1C-E) and S1P lyase (Fig. 2C-E). Staining for both markers were mainly cytoplasmic and membranous and varied from weak to strong. Nuclear positivity of SphK1 was also seen in some cases. Adenocarcinomas showed the strongest expression of both SphK1 and S1P lyase $(\mathrm{P}<0.0001$ and $\mathrm{P}=0.001$ respectively; Fig. 3A-B). Staining for both markers was conspicuously absent in the surrounding stroma. IgG control staining for SphK1 and S1P lyase respectively are shown in Fig. 1F and Fig. 2F. Overexpression of SphK1 was significantly associated with more advanced disease stage $(\mathrm{P}=0.008$; Fig. 3C), while there was a non-significant trend of S1P lyase association with advanced stage ( $\mathrm{P}=0.06$; Fig. 3D).

The predictive value of SphK1 and S1P lyase in NSCLC patients. The Kaplan-Meier survival analysis showed that overexpression of SphK1 (dichotomized for median) was significantly associated with poor overall survival in patients treated with platinum based chemotherapy $(\mathrm{P}=0.035)$. However, the overall survival difference was not significant in patients treated with surgery only. With regards to disease free survival, there was a trend to high SphK1 expression association with poor outcome $(\mathrm{P}=0.09)$, which was not seen in patients treated by surgery alone (Fig. 4).

We found no statistically significant association between S1P lyase expression and survival outcomes (Fig. 5) and no inverse correlation between SphK1 and S1P lyase as reported for prostate cancer (27).

\section{Discussion}

In the present study, we analyzed the prognostic and predictive value of SphK1 and S1P lyase, two key enzymes that control S1P content in cells, in patients with NSCLC treated with adjuvant chemotherapy based on carboplatin and navelbine. NSCLC samples exhibited various immunostaining patterns for both SphK1 and S1P lyase.

We found that SphK1 staining was mainly cytosolic and membranous with the highest expression seen in adenocarcinomas. Our observations are in line with the findings of Johnson et al (39), who originally evaluated the expression of SphK1 in normal and cancerous lung tissue. Nuclear positivity 


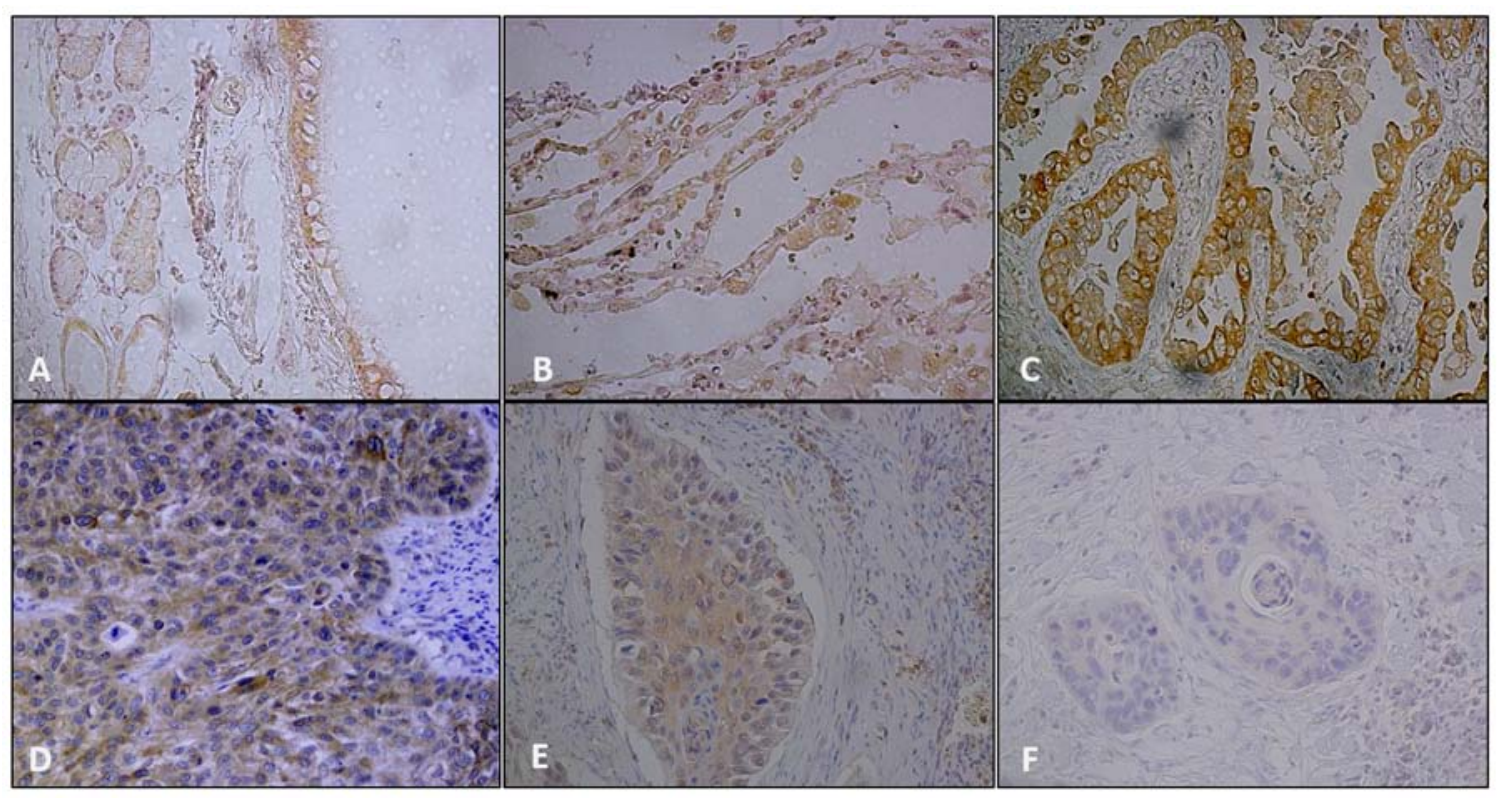

Figure 2. S1P lyase staining in normal adjacent and NSCLC tissues. (A) S1P lyase staining in normal pseudo-stratified columnar epithelial cells and (B) type II pneumocytes (IHC staining; magnification, x200). (C) S1P lyase staining in adenocarcinoma of the lung and (D) squamous cell carcinoma of the lung. (E) Loss of S1P lyase expression in large cell carcinoma of the lung. (F) Matched immunoglobulin G control (IHC staining; magnification, x200). NSCLC, non-small cell lung cancer; IHC staining, immunohistochemical staining; S1P, sphingosine 1-phosphate.

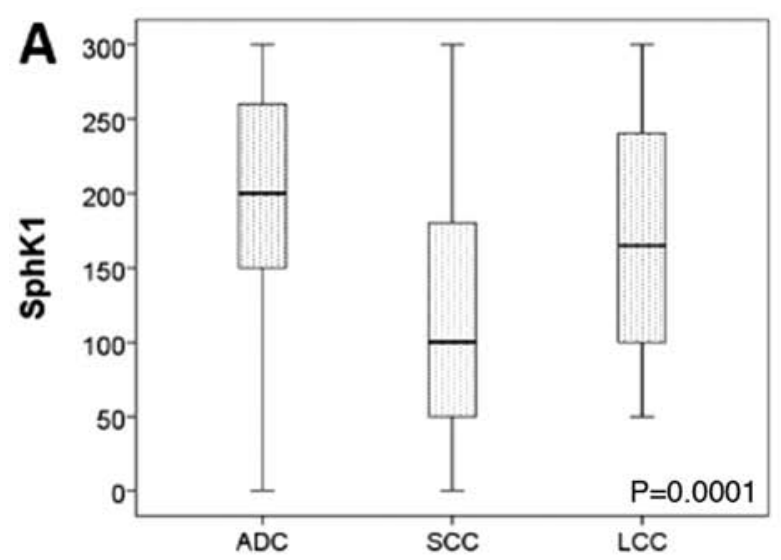

Histological subtypes

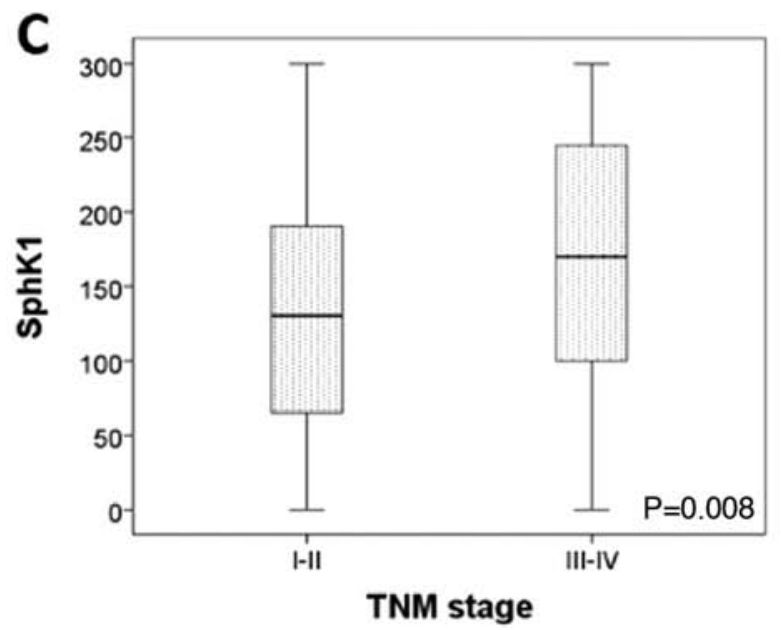

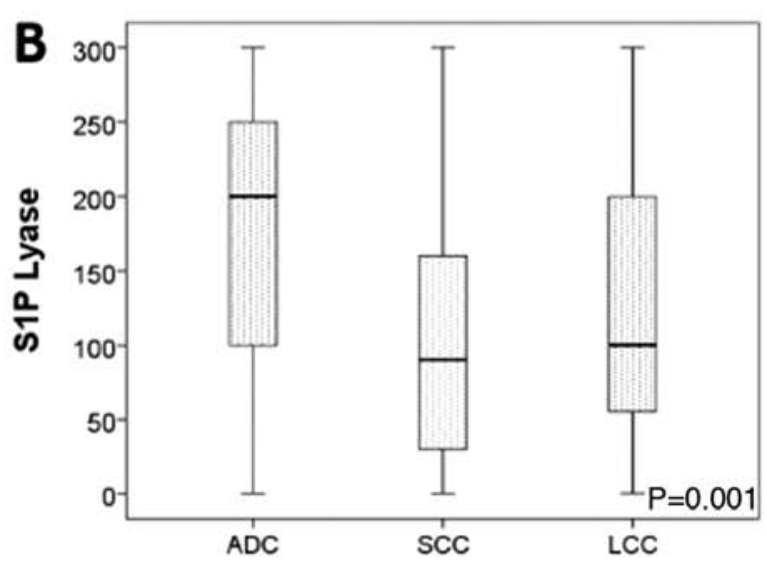

Histological subtypes

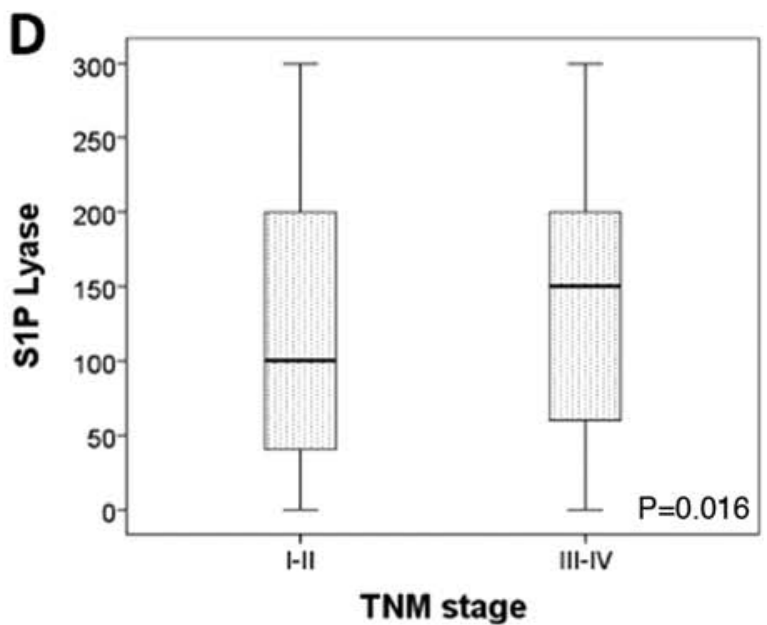

Figure 3. Distribution of SphK1 and S1P lyase in different histological subtypes and grades of NSCLC. (A) The highest expression of SphK1 was observed in ADC, followed by LCC and SCC ( $\mathrm{P}<0.0001)$. (B) The highest expression of S1P lyase was observed in ADC, followed by LCC and SCC (P=0.001). (C) SphK1 expression is higher in stage III-IV patients when compared with stage I-II ones ( $\mathrm{P}=0.008)$. (D) S1P lyase expression is higher in stage III-IV, but not significantly difference $(\mathrm{P}=0.016)$. NSCLC, non-small cell lung cancer; ADC, adenocarcinoma; SCC, squamous cell carcinoma; LCC, large cell carcinoma; TNM, tumor, node, metastases; SphK1, sphingosine kinase-1; S1P, sphingosine 1-phosphate. 

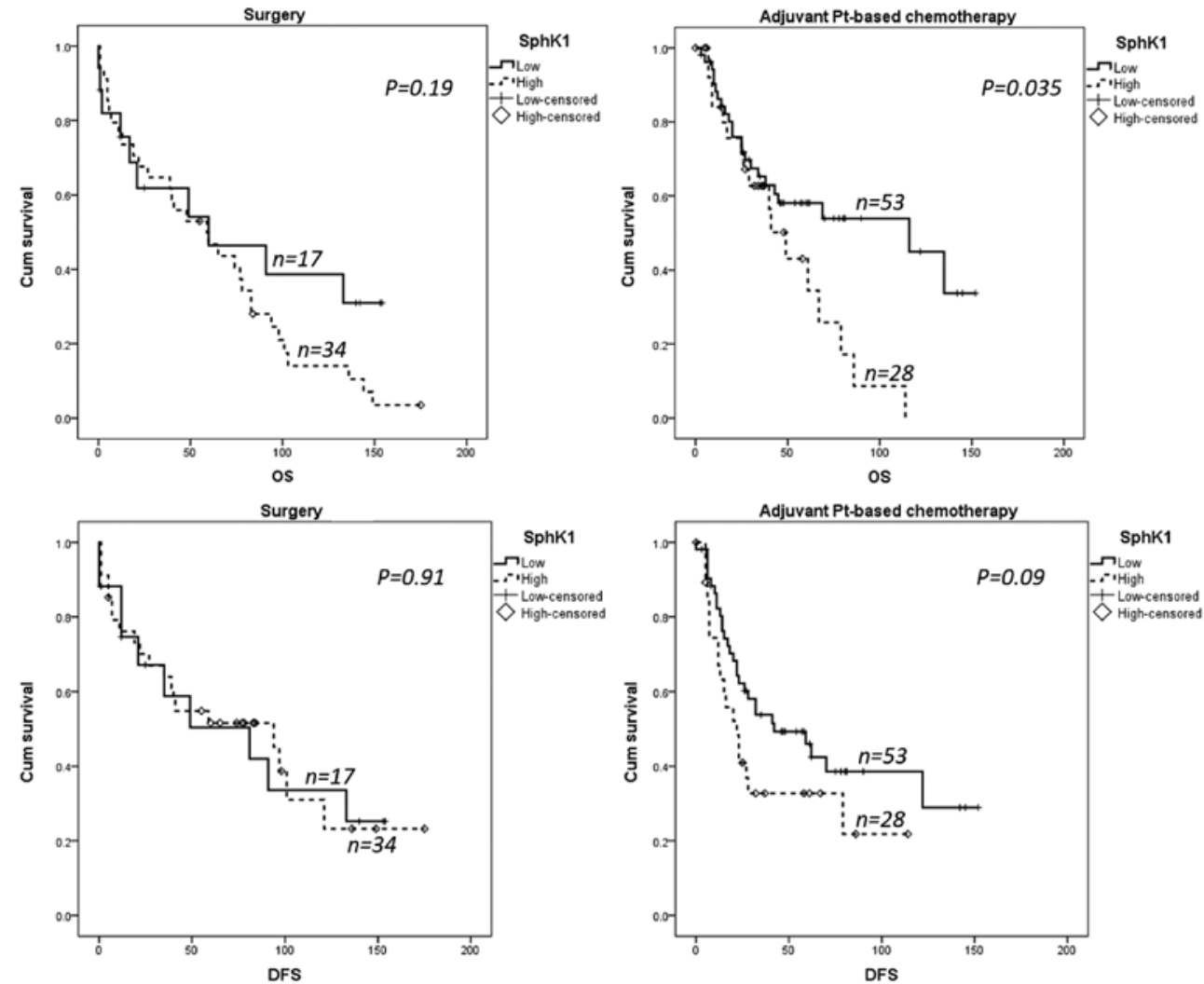

Figure 4. Kaplan-Meier survival curves for dichotomized SphK1 expression. The overexpression of SphK1 is associated with significantly lower OS and DFS in patients treated with carboplatin and navelbine, whilst there is no significant association between SphK1 expression and survival outcomes in patients treated with surgery only. SphK1, sphingosine kinase-1; Pt, platinum; Cum survival, cumulative survival; OS, overall survival; DFS, disease free survival.
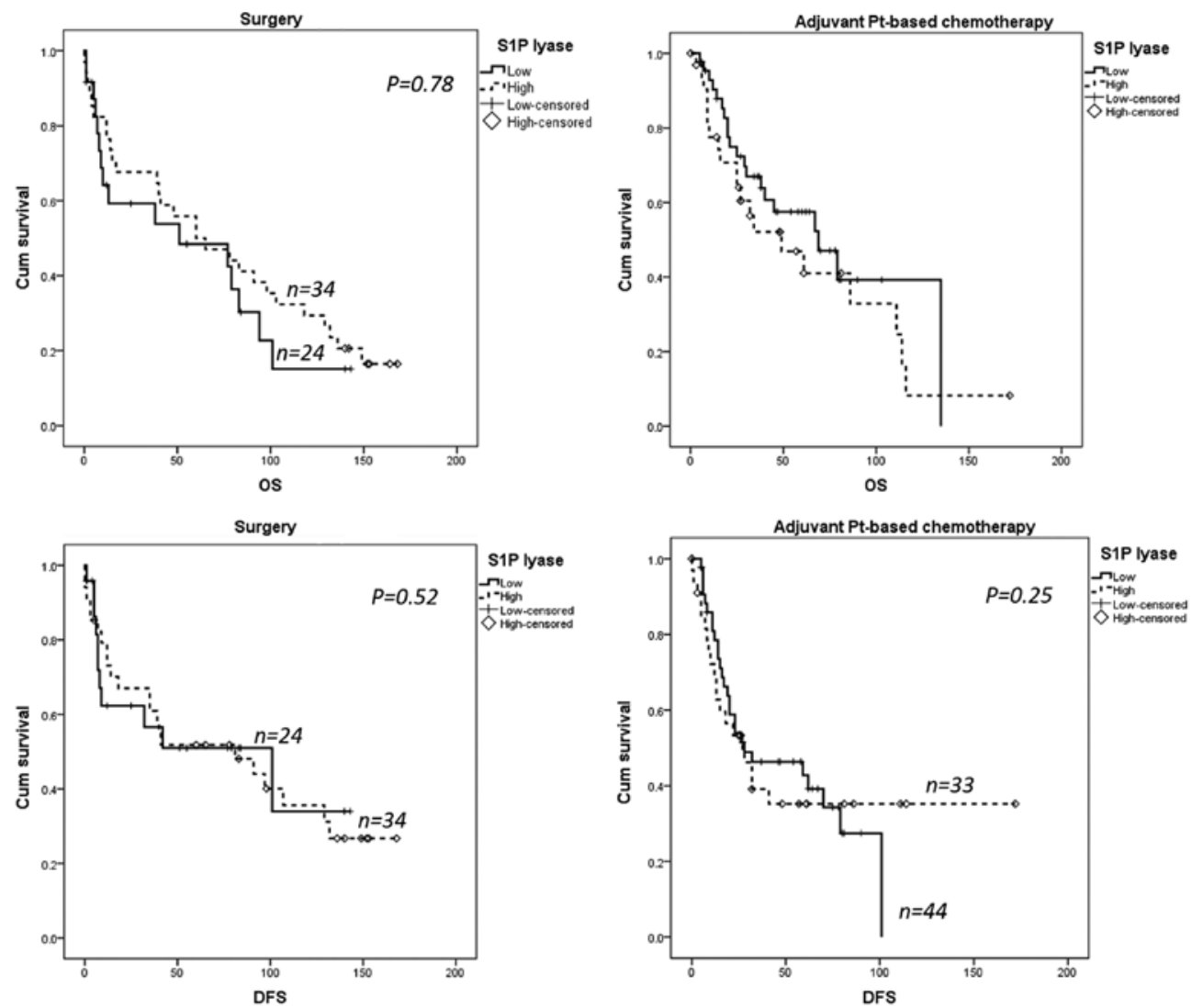

Figure 5. Kaplan-Meier survival curves for dichotomized S1P lyase expression. The overexpression of S1P lyase is not associated with OS and DFS neither in surgery nor in the adjuvant treatment group of patients. S1P, sphingosine 1-phosphate; Pt, platinum; Cum survival, cumulative survival; OS, overall survival; DFS, disease free survival. 
of SphK1 has rarely been observed, however the biological significance of this expression is not known.

So far, only one study appears to have examined the prognostic and predictive role of SphK1 in NSCLC. In 2011, Song et al (30) showed that immunohistochemical expression of SphK1 was markedly increased in NSCLC and, in relation to clinical stage and TNM classification. In agreement with this study, we found a statistically significant correlation between SphK1 expression and clinical stage. Significantly, overall survival of patients with high SphK1 expression was found to be shorter than in patients with low SphK1 expression (30). However, these authors did not stratify patients according to adjuvant chemotherapy. To the best of our knowledge, no clinical studies have ever examined the role of SphK1 in platinum-based chemotherapy resistance in patients. We show for the first time that high SphK1 expression is associated with shorter overall survival and increased risk of disease relapse in patients with NSCLC treated with adjuvant chemotherapy.

Several studies have examined the relationship between SphK1 and platinum sensitivity in vitro. In colon cancer cells, it has been shown that downregulation of SphK1 enhances cisplatin sensitivity (40). In gastroesophageal cancer cells, cisplatin resistance is correlated with increased SphK1 mRNA expression (41). With regards to lung cancer, cisplatin-resistant lung cancer cell line H460/DDP has been characterized by overexpression of SphK1 compared to the parental cell line (42). Collectively, these data suggest an important role of SphK1 in mediating cisplatin sensitivity, at least in vitro.

In conclusion, the present study is the first to examine the immunohistochemical expression of both S1P lyase and SphK1 in NSCLC in relationship to survival in patients treated with adjuvant chemotherapy. Our data validate the prognostic role of SphK1 expression in patients with NSCLC, including those treated with adjuvant platinum-based chemotherapy.

\section{Acknowledgements}

Not applicable.

\section{Funding}

The present study was supported by grants from the Ministry of Education Czech Republic (grant nos. MSMT 61875921, NPS I LO1304 and RVO:61989592), the Ministry of Health Czech Republic (grant nos. IGA MZ CR 10259-3, 9959-3, AZV NV19-03-00069 and RVO:FNOL00098892), by internal grants from Palacký University (grant nos. 91110281 and LF_2019_004), the National Health and Medical Research Council of Australia, the Programme VLTAVA (French Embassy, Prague), the CNRS (France) and the Ligue Nationale contre le Cancer (France).

\section{Availability of data and materials}

The datasets generated and/or analyzed during the present study are available from the corresponding author on reasonable request.

\section{Authors' contributions}

JS, MG, LC and TT conducted the histopathological diagnoses and the re-classification of tumor samples, and evaluated and scored cases for SphK1 and S1P lyase immunohistochemical expression. GM and GK performed the major statistical analyses of the data. MJ optimized the initial IHC staining and performed the preliminary analyses. VK, IG and PS diagnosed the patients with lung cancer, collected the clinical data and obtained the follow-up information. JK performed the surgery and provided the samples for the study. SP and MM provided and validated the molecular biology tools for the study; SP made the antibodies and MM assessed the antibodies. JS and MG contributed to the design of the study, wrote the manuscript and performed the statistical analysis. OC contributed to the design of the study, analyzed the data and wrote the manuscript.

\section{Ethics approval and consent to participate}

Informed, written consent for the use of tissues and clinical data was obtained from all participants and the studies were carried out according to the latest Declaration of Helsinki. The procedures were approved by the local Ethics Committee on $06 / 29 / 2011$.

\section{Patient consent for publication}

Not applicable.

\section{Competing interests}

The authors declare that they have no competing interests.

\section{References}

1. Jemal A, Bray F, Center MM, Ferlay J, Ward E and Forman D: Global cancer statistics. CA Cancer J Clin 61: 69-90, 2011.

2. Arriagada R, Bergman B, Dunant A, Le Chevalier T, Pignon JP and Vansteenkiste J; International Adjuvant Lung Cancer Trial Collaborative Group: Cisplatin-based adjuvant chemotherapy in patients with completely resected non-small-cell lung cancer. $\mathrm{N}$ Engl J Med 350: 351-360, 2004.

3. Pignon JP, Tribodet H, Scagliotti GV, Douillard JY, Shepherd FA, Stephens RJ, Dunant A, Torri V, Rosell R, Seymour L, et al; LACE Collaborative Group: Lung adjuvant cisplatin evaluation: A pooled analysis by the LACE Collaborative Group. J Clin Oncol 26: 3552-3559, 2008.

4. Douillard JY, Rosell R, De Lena M, Carpagnano F, Ramlau R, Gonzáles-Larriba JL, Grodzki T, Pereira JR, Le Groumellec A, Lorusso $\mathrm{V}$, et al: Adjuvant vinorelbine plus cisplatin versus observation in patients with completely resected stage IB-IIIA non-small-cell lung cancer (Adjuvant Navelbine International Trialist Association [ANITA]): A randomised controlled trial. Lancet Oncol 7: 719-727, 2006.

5. Zatloukal P, Petruzelka L, Zemanova M, Havel L, Janku F, Judas L, Kubik A, Krepela E, Fiala P and Pecen L: Concurrent versus sequential chemoradiotherapy with cisplatin and vinorelbine in locally advanced non-small cell lung cancer: A randomized study. Lung Cancer 46: 87-98, 2004.

6. Scheper RJ, Broxterman HJ, Scheffer GL, Kaaijk P, Dalton WS, van Heijningen TH, van Kalken CK, Slovak ML, de Vries EG, van der Valk P, et al: Overexpression of a M(r) 110,000 vesicular protein in non-P-glycoprotein-mediated multidrug resistance. Cancer Res 53: 1475-1479, 1993. 
7. Marchetti S, de Vries NA, Buckle T, Bolijn MJ, van Eijndhoven MA, Beijnen JH, Mazzanti R, van Tellingen O and Schellens JH: Effect of the ATP-binding cassette drug transporters ABCB1, ABCG2 and $\mathrm{ABCC} 2$ on erlotinib hydrochloride (Tarceva) disposition in in vitro and in vivo pharmacokinetic studies employing Bcrp1-/-/Mdrla/1b-/- (triple-knockout) and wild-type mice. Mol Cancer Ther 7: 2280-2287, 2008.

8. Ozvegy-Laczka C, Cserepes J, Elkind NB and Sarkadi B: Tyrosine kinase inhibitor resistance in cancer: Role of $\mathrm{ABC}$ multidrug transporters. Drug Resist Updat 8: 15-26, 2005.

9. Berger W, Setinek U, Hollaus P, Zidek T, Steiner E, Elbling L, Cantonati H, Attems J, Gsur A and Micksche M: Multidrug resistance markers P-glycoprotein, multidrug resistance protein 1 , and lung resistance protein in non-small cell lung cancer: Prognostic implications. J Cancer Res Clin Oncol 131: 355-363, 2005.

10. Ikuta K, Takemura K, Sasaki K, Kihara M, Nishimura M, Ueda N, Naito S, Lee E, Shimizu E and Yamauchi A: Expression of multidrug resistance proteins and accumulation of cisplatin in human non-small cell lung cancer cells. Biol Pharm Bull 28: 707-712, 2005

11. Berger W, Elbling L, Hauptmann E and Micksche M: Expression of the multidrug resistance-associated protein (MRP) and chemoresistance of human non-small-cell lung cancer cells. Int J Cancer 73: 84-93, 1997.

12. Yano K: Lipid metabolic pathways as lung cancer therapeutic targets: A computational study. Int J Mol Med 29: 519-529, 2012.

13. Futerman $\mathrm{AH}$ and Hannun YA: The complex life of simple sphingolipids. EMBO Rep 5: 777-782, 2004.

14. Cuvillier O and Levade T: Enzymes of sphingosine metabolism as potential pharmacological targets for therapeutic intervention in cancer. Pharmacol Res 47: 439-445, 2003

15. Morad SA and Cabot MC: Ceramide-orchestrated signalling in cancer cells. Nat Rev Cancer 13: 51-65, 2013.

16. Cuvillier O: Sphingosine in apoptosis signaling. Biochim Biophys Acta 1585: 153-162, 2002.

17. Pitson SM: Regulation of sphingosine kinase and sphingolipid signaling. Trends Biochem Sci 36: 97-107, 2011.

18. Maceyka M, Harikumar KB, Milstien S and Spiegel S: Sphingosine-1-phosphate signaling and its role in disease. Trends Cell Biol 22: 50-60, 2012.

19. Cuvillier O, Ader I, Bouquerel P, Brizuela L, Gstalder C and Malavaud B: Hypoxia, therapeutic resistance, and sphingosine 1-phosphate. Adv Cancer Res 117: 117-141, 2013.

20. Mendelson K, Evans T and Hla T: Sphingosine 1-phosphate signalling. Development 141: 5-9, 2014.

21. Cuvillier O: Downregulating sphingosine kinase-1 for cancer therapy. Expert Opin Ther Targets 12: 1009-1020, 2008.

22. Cuvillier O, Pirianov G, Kleuser B, Vanek PG, Coso OA Gutkind S and Spiegel S: Suppression of ceramide-mediated programmed cell death by sphingosine-1-phosphate. Nature 381: 800-803, 1996

23. Bonhoure E, Pchejetski D, Aouali N, Morjani H, Levade T, Kohama T and Cuvillier O: Overcoming MDR-associated chemoresistance in HL-60 acute myeloid leukemia cells by targeting sphingosine kinase-1. Leukemia 20: 95-102, 2006.

24. Pchejetski D, Golzio M, Bonhoure E, Calvet C, Doumerc N, Garcia V, Mazerolles C, Rischmann P, Teissié J, Malavaud B, et al: Sphingosine kinase-1 as a chemotherapy sensor in prostate adenocarcinoma cell and mouse models. Cancer Res 65: 11667-11675, 2005.

25. Guillermet-Guibert J, Davenne L, Pchejetski D, Saint-Laurent N, Brizuela L, Guilbeau-Frugier C, Delisle MB, Cuvillier O, Susini $\mathrm{C}$ and Bousquet $\mathrm{C}$ : Targeting the sphingolipid metabolism to defeat pancreatic cancer cell resistance to the chemotherapeutic gemcitabine drug. Mol Cancer Ther 8: 809-820, 2009.

26. Pchejetski D, Bohler T, Brizuela L, Sauer L, Doumerc N, Golzio M, Salunkhe V, Teissié J, Malavaud B, Waxman J, et al: FTY720 (fingolimod) sensitizes prostate cancer cells to radiotherapy by inhibition of sphingosine kinase-1. Cancer Res 70: 8651-8661, 2010.

27. Brizuela L, Ader I, Mazerolles C, Bocquet M, Malavaud B and Cuvillier O: First evidence of sphingosine 1-phosphate lyase protein expression and activity downregulation in human neoplasm: Implication for resistance to therapeutics in prostate cancer. Mol Cancer Ther 11: 1841-1851, 2012.
28. Gstalder C, Ader I and Cuvillier O: FTY720 (Fingolimod) Inhibits HIF1 and HIF2 Signaling, Promotes Vascular Remodeling, and Chemosensitizes in Renal Cell Carcinoma Animal Model. Mol Cancer Ther 15: 2465-2474, 2016

29. Ito H, Yoshida K, Murakami M, Hagiwara K, Sasaki N, Kobayashi M, Takagi A, Kojima T, Sobue S and Suzuki M: Heterogeneous sphingosine-1-phosphate lyase gene expression and its regulatory mechanism in human lung cancer cell lines. Biochim Biophys Acta 1811: 119-128, 2011.

30. Song L, Xiong H, Li J, Liao W, Wang L, Wu J and Li M: Sphingosine kinase-1 enhances resistance to apoptosis through activation of PI3K/Akt/NF- $x \mathrm{~B}$ pathway in human non-small cell lung cancer. Clin Cancer Res 17: 1839-1849, 2011.

31. Li J, Guan HY, Gong LY, Song LB, Zhang N, Wu J, Yuan J, Zheng YJ, Huang ZS and Li M: Clinical significance of sphingosine kinase-1 expression in human astrocytomas progression and overall patient survival. Clin Cancer Res 14: 6996-7003, 2008.

32. Zhang Y, Wang Y, Wan Z, Liu S, Cao Y and Zeng Z: Sphingosine kinase 1 and cancer: A systematic review and meta-analysis. PLoS One 9: e90362, 2014.

33. Ruckhäberle E, Karn T, Denkert C, Loibl S, Ataseven B, Reimer T, Becker S, Holtrich U, Rody A, Darb-Esfahani S, et al: Predictive value of sphingosine kinase 1 expression in neoadjuvant treatment of breast cancer. J Cancer Res Clin Oncol 139: 1681-1689, 2013.

34. Sutphen R, Xu Y, Wilbanks GD, Fiorica J, Grendys EC Jr, LaPolla JP, Arango H, Hoffman MS, Martino M, Wakeley K, et al: Lysophospholipids are potential biomarkers of ovarian cancer. Cancer Epidemiol Biomarkers Prev 13: 1185-1191, 2004

35. Malavaud B, Pchejetski D, Mazerolles C, de Paiva GR, Calvet C, Doumerc N, Pitson S, Rischmann P and Cuvillier O: Sphingosine kinase-1 activity and expression in human prostate cancer resection specimens. Eur J Cancer 46: 3417-3424, 2010.

36. Serra M and Saba JD: Sphingosine 1-phosphate lyase, a key regulator of sphingosine 1-phosphate signaling and function. Adv Enzyme Regul 50: 349-362, 2010.

37. Oskouian B, Sooriyakumaran P, Borowsky AD, Crans A, Dillard-Telm L, Tam YY, Bandhuvula $\mathrm{P}$ and Saba JD: Sphingosine-1-phosphate lyase potentiates apoptosis via p53and p38-dependent pathways and is down-regulated in colon cancer. Proc Natl Acad Sci USA 103: 17384-17389, 2006.

38. Min J, Van Veldhoven PP, Zhang L, Hanigan MH, Alexander H and Alexander S: Sphingosine-1-phosphate lyase regulates sensitivity of human cells to select chemotherapy drugs in a p38-dependent manner. Mol Cancer Res 3: 287-296, 2005.

39. Johnson KR, Johnson KY, Crellin HG, Ogretmen B, Boylan AM, Harley RA and Obeid LM: Immunohistochemical distribution of sphingosine kinase 1 in normal and tumor lung tissue. $\mathrm{J}$ Histochem Cytochem 53: 1159-1166, 2005.

40. Qin L, Liu S, Qin M, Wu W, Qin N, Fu Z, Xu C, Huang J and Lai M: Down-regulation of sphingosine kinase 1 (SphK1) enhances the chemosensitivity to cisplatin in human colon cancer RKO cells. Xi Bao Yu Fen Zi Mian Yi Xue Za Zhi 33: 623-629, 2017 (In Chinese)

41. Matula K, Collie-Duguid E, Murray G, Parikh K, Grabsch H, Tan P, Lalwani S, Garau R, Ong Y, Bain G, et al: Regulation of cellular sphingosine-1-phosphate by sphingosine kinase 1 and sphingosine-1-phopshate lyase determines chemotherapy resistance in gastroesophageal cancer. BMC Cancer 15: 762, 2015.

42. Gao J, Tian ML and Song LP: The role of SPHK-1 in non-small cell lung cancer drug-resistant cell line H460. J Xi'an Jiaotong Univ 38: 172-175, 2017 (In Chinese).

This work is licensed under a Creative Commons Attribution-NonCommercial-NoDerivatives International (CC BY-NC-ND 4.0) License. 